\title{
Sociodemographic Variation of Caries Risk Factors in Toddlers and Caregivers
}

\author{
G. J. Eckert, ${ }^{1}$ R. Jackson, ${ }^{2}$ and M. Fontana ${ }^{3}$ \\ ${ }^{1}$ Division of Biostatistics, Indiana University School of Medicine, Indianapolis, IN 46202, USA \\ ${ }^{2}$ Department of Preventive and Community Dentistry, Indiana University School of Dentistry, Indianapolis, IN 46202, USA \\ ${ }^{3}$ Department of Cariology, Restorative Sciences and Endodontics, University of Michigan School of Dentistry, Ann Arbor, \\ MI 48109-1078, USA
}

Correspondence should be addressed to M. Fontana, mfontan@umich.edu

Received 17 December 2009; Revised 5 May 2010; Accepted 29 July 2010

Academic Editor: W. Murray Thomson

Copyright ( 2010 G. J. Eckert et al. This is an open access article distributed under the Creative Commons Attribution License, which permits unrestricted use, distribution, and reproduction in any medium, provided the original work is properly cited.

Objectives. Dental caries is the most common chronic childhood disease, with numerous identified risk factors. Risk factor differences could indicate the need to target caregiver/patient education/preventive care intervention strategies based on population and/or individual characteristics. The purpose of this study was to evaluate caries risk factors differences by race/ethnicity, income, and education. Methods. We enrolled 396 caregiver-toddler pairs and administered a 105-item questionnaire addressing demographics, access to care, oral bacteria transmission, caregiver's/toddler's dental and medical health practices, caregiver's dental beliefs, and caregiver's/toddler's snacking/drinking habits. Logistic regressions and ANOVAs were used to evaluate the associations of questionnaire responses with caregiver's race/ethnicity, income, and education. Results. Caregivers self-identified as Non-Hispanic African-American (44\%), Non-Hispanic White (36\%), Hispanic (19\%), and "other" (1\%). Differences related to race/ethnicity, income, and education were found in all risk factor categories. Conclusions. Planning of caregiver/patient education/preventive care intervention strategies should be undertaken with these caries risk factor differences kept in mind.

\section{Introduction}

According to the first-ever U.S. Surgeon General's report on oral health published in May 2000 [1], dental caries is the most common chronic childhood disease. In addition, most $(75 \%-80 \%)$ of the caries in children in this country occur in a small segment of the population $(20 \%-25 \%)$ [2], and this problem is particularly prevalent in minorities and immigrants and lower-income children [3]. Unfortunately, the funds to provide preventive care to all children who are either from a minority population or the lower SES levels are simply not available. Therefore, it is reasonable to attempt to identify those at highest risk in these populations and concentrate what limited financial and manpower resources are available in these "highest of the high" [4]. Additionally, the cultural, and behavioral determinants of disease and the barriers to access dental health services in these populations may be dissimilar to those in other social groups [5].
Understanding these differences may eventually influence different preventive strategies and alternative ways to help health providers to communicate with these groups in order to enhance health related behaviors and conditions. Therefore, identifying a child's level of risk for development of dental caries and the reasons behind it are necessary first steps in managing dental caries.

Risk-based prevention and disease management have been recognized as the cornerstones of modern caries management [6-8], especially in young children [8-10]. The fact that the existence of past restorations is one of the greatest indicators of risk for the development of new caries lesions $[9,11]$ only proves that the act of surgically treating the caries lesion does little to reduce the risk of developing the next lesion, generally makes no significant difference to bacterial loading, nor on the enactment of selfpromoting health behaviors such as brushing one's teeth [1214]. The etiology of the dental caries process is multifactorial 
in nature and involves a combination of factors including diet, a susceptible host, and microflora, which interplay with a variety of social, cultural and behavioral factors. Additionally, most young children appear to acquire some cariogenic microorganisms (i.e., mutans streptococci-MS) from their mothers or primary caregivers [15]. Transmission happens through saliva and can be affected among other variables by the frequency of the contact (e.g., sharing of food and utensils, kissing, etc.), which could have cultural and behavioral determinants and, therefore, may vary among different ethnic and cultural population groups. Because of the multifactorial nature of the dental caries disease process, and the fact that the disease is very dynamic, but not continuous (e.g., lesions can progress and/or regress), studies on risk assessment tend to be complex, with a multitude of variables challenging the prediction at different times during the life of an individual [10]. For a clinician, the concepts of assessment of risk and prognosis are an important part of clinical decision making, individualized counseling, and anticipatory guidance.

In addition, risk factors may vary based on race, culture, and ethnicity [16-21]. Unfortunately, there are very few high-quality, longitudinal caries risk studies focusing on infants and toddlers $[10,22]$. Furthermore, existing studies have been conducted primarily in selective populations in Northern Europe [23-29], diminishing the generalizability of these results to the US population. One recent study has been conducted in a low SES, African-American U.S. community [30]. In addition, Gao et al. [31] have recently suggested that practical biopsychosocial caries risk models without biological markers, such as the one tested here, are effective (sensitivity/specificity was $82 \% / 73 \%$ ) and promise to be cost-effective to reach children in a variety of settings.

Others have studied dental habits, attitudes, and beliefs in a range of settings. However, these studies have drawbacks in application to caregivers of toddlers due to the populations studied (age, race/ethnicity, and/or geographic location) and due to the range of topics covered. Dental habits, beliefs, and attitudes have been studied in adults [32-40], finding variability in beliefs and attitudes which may affect their own dental outcomes, but was not necessarily examined in the context of adults who were caring for toddlers. In parents of young children in Great Britain, knowledge and attitudes were found to vary due to education, ethnicity, and area of residence [41]. Dental knowledge, attitudes, and practices may also be impacted by the overall health of the child. Research has shown beliefs were found to differ between parents of children with and without congenital heart disease [42]. Relationships of caries in 3-year olds in Japan with child-rearing behaviors and mother's health behaviors were examined [43], finding a stronger association with the childrelated behaviors than the mother's behaviors.

The purpose of this study was to evaluate how known caries risk factors evaluated longitudinally in young U.S. children differ by the ethnicity, income, and education of the caregiver. These factors had been identified through previous research as possible risk factors and were included as part of a one-year longitudinal risk study. If differences were found in the risk factors, as expected, this could indicate the need to target caregiver/patient education and preventive care intervention strategies based on the characteristics of the population or individual.

\section{Methods}

The study population included caregiver-toddler pairs in Indianapolis and Connersville, Indiana, USA. Subjects were recruited through four sites: (1) a primary-care-based studyrecruitment system affiliated with a large metropolitan hospital serving a generally underserved and lower-income population, (2) the Oral Health Research Institute of the Indiana University School of Dentistry, (3) the Hispanic Center of Indianapolis, and (4) the rural town of Connersville. At sites 2-4 above, recruitment was done by radio and newspaper advertisements, as well as contacting an IRB-approved database of people who had participated in previous studies with us at those locations. The adult accompanying the child was required to self-identify as being the primary caregiver for the child. We defined "primary caregiver" (PCG) as the individual consistently responsible for the housing, health, and safety of the child. Toddlers ranged in age from 16 to 36 months at the time of recruitment, and were generally healthy based on the caregivers' responses to a medical history questionnaire. The study protocol, letter of informational consent, and other supporting documents were approved by the Indiana University Medical Center Institutional Review Board prior to their use. Written informed consent was obtained from all PCGs (and parent/legal guardian if different from the child's PCG) prior to their enrollment.

A caries risk questionnaire was developed to include questions related both to the PCG and the child regarding social, cultural, functional, psychological, sociodemographic, dietary, and biological factors that may affect transmission, development of caries, and access to care in these populations. Many of the questions were taken or modified from other risk assessment questionnaires and tools. An external review panel, which ranged from practitioners (pediatric dentists and pediatric physicians) to experts in the area of cariology, predictive modeling, and behavioral science, were provided a copy of the questionnaire and asked to review/edit the questionnaire to ensure that the initial draft of the questionnaire was reasonable in scope and that no established risk indicator had been omitted. After receiving separate IRB approval, the draft questionnaire was tested in a panel of 25 caregivers (nearly equal numbers of English and Spanish speaking), similar to the target population (had to consent to participate and have a child between 18 and 36 months of age), to ensure that the questions that were asked were worded appropriately for nonprofessionals, to eliminate jargon, to define or eliminate confusing terminology (e.g., words such as frequent, often, etc.), to ensure use of culturally-sensitive language, to finalize the organization of the items, and to verify the consistency of the structure of similar items. In most cases, it was believed that the majority of persons to be interviewed as PCG would be the mothers, but others (e.g., grandmothers, fathers) were to be included if it was found that they were responsible for 


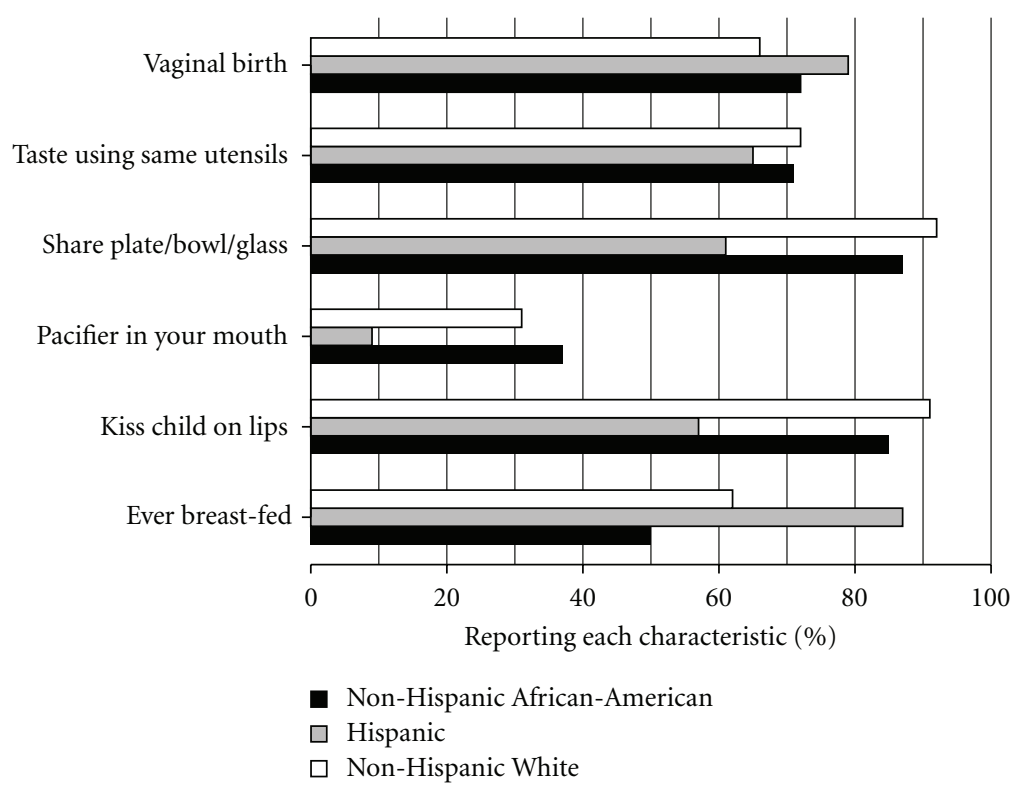

Figure 1: Relationships of race/ethnicity with oral bacteria transmission questionnaire responses (\% responding "Yes"). Analyses were performed for each questionnaire item using multivariable logistic regression models with race/ethnicity, income, and education as predictors. Differences among race/ethnicity groups were found for "ever breast fed" $(P=.0004$, highest for Hispanics), "kiss child on lips" ( $P=.0001$, lowest for Hispanics), "share plate/bowl/glass" $(P=.0001$, lowest for Hispanics $)$, and "pacifier in your mouth" $(P=.0156$, lowest for Hispanics).

providing the largest percentage of the child's care. Based on the results of the focus group data, some changes were made in the wording of questions, some questions were eliminated and some were reordered, and the questionnaire was finalized.

The final version of the questionnaire, which included 105 items (see Appendix), was administered by study personnel to the PCG $(n=396)$ using a multiple choice format, with responses recorded directly into a web-based database system. The caregiver chose whether to use the English or Spanish version of the questionnaire. Topics included in the questionnaire were categorized into: demographics, access to care, possible routes for oral bacteria transmission, usual dental and medical health practices of the caregiver and the toddler, dental beliefs of the caregiver, and snacking and drinking habits of the caregiver and the toddler. In addition, a subset of the caregivers $(n=250)$ was invited to participate in an additional investigation of health literacy. After additional informed consent, caregivers were administered the Short Test of Functional Health Literacy in Adults (STOFHLA) [44], with the caregiver given the option of using either the English or Spanish version.

The associations of PCG education and household income with race/ethnicity were tested using ANOVA, and Spearman correlation coefficients were calculated to measure the association between PCG education and household income. For the analyses, education levels were collapsed into 8th grade or lower, some high school, completed high school, some college, 4-year college, and postgraduate. We analyzed each survey item individually to assess the need to modify caregiver/patient education and preventive care intervention strategies based on demographic factors. To examine the associations of individual survey items (dependent variables in separate models) with the caregiver's race/ethnicity, the caregiver's education, and the household income simultaneously (three independent variables), multivariable logistic and linear regression analyses were used for survey items with qualitative responses and quantitative responses, respectively; thus race/ethnicity comparisons are adjusted for income and education, income comparisons are adjusted for race/ethnicity and education, and education comparisons are adjusted for race/ethnicity and income. $P$-values presented for the race/ethnicity comparisons are for the overall tests for any effect among the three groups; individual pairwise results are presented when significant but the $P$-values are not provided. Odds ratios presented for education and income are for a one-level change in the response categories. A 5\% significance level was used for all analyses; although a large number of tests were performed, we did not adjust for multiple testing. A less restrictive cutoff without a multiple-testing adjustment provides a larger pool of possible differences that can be targeted when revising caregiver/patient education and preventive care intervention strategies.

\section{Results}

The study enrolled 396 caregiver-toddler pairs at baseline (two additional pairs were screened but did not qualify due to the child's medical condition), which is estimated to be approximately $70 \%$ of those invited to participate. Nearly all of the primary caregivers (378) were the child's mother, 
TABle 1: Relationships of race/ethnicity, education, and income with questionnaire responses for demographics and access to care. Association of PCG education with race/ethnicity was tested using ANOVA. Remaining analyses were performed for each questionnaire item using multivariable logistic regression models with race/ethnicity, income, and education as predictors. Race/ethnicity $P$-values are for the overall test of any difference among the three groups. Questionnaire item numbers are listed in the left-most column (see the appendix for questionnaire). $\mathrm{N}(\%)$ for race/ethnicity, odds ratio $(\mathrm{OR})$ for Education and Income. NH-AA = Non-Hispanic African-American, $\mathrm{NH}-\mathrm{W}=$ Non-Hispanic White.

\begin{tabular}{|c|c|c|c|c|c|c|c|c|c|}
\hline & \multicolumn{4}{|c|}{ PCG race/ethnicity } & \multicolumn{2}{|c|}{ PCG education } & \multicolumn{2}{|c|}{ PCG income } \\
\hline & & $\begin{array}{l}\text { Hispanic } \\
(n=75)\end{array}$ & $\begin{array}{l}\text { NH-AA } \\
(n=175)\end{array}$ & $\begin{array}{c}\text { NH-W } \\
(n=141)\end{array}$ & $P$-value & OR & $P$-value & OR & $P$-value \\
\hline Q83 & PCG education ${ }^{\mathrm{a}}$ & & & & .0001 & & & & \\
\hline & Less than high school & $13(17 \%)$ & $0(0 \%)$ & $3(2 \%)$ & & & & & \\
\hline & $1-3$ years high school & $20(27 \%)$ & $33(19 \%)$ & $20(14 \%)$ & & & & & \\
\hline & 4 years high school & $22(29 \%)$ & $66(38 \%)$ & $45(32 \%)$ & & & & & \\
\hline & $1-3$ years college & $12(16 \%)$ & $46(26 \%)$ & $35(25 \%)$ & & & & & \\
\hline & 4 years college & $6(8 \%)$ & $21(12 \%)$ & $28(20 \%)$ & & & & & \\
\hline & Postgraduate & $2(3 \%)$ & $9(5 \%)$ & $10(7 \%)$ & & & & & \\
\hline Q94 & Difficult to understand info from dentist/MD & $23(31 \%)$ & $7(4 \%)$ & $10(7 \%)$ & .0025 & 0.4 & .0001 & 1.0 & .8900 \\
\hline Q34 & City drinking water & $33(44 \%)$ & $92(53 \%)$ & $99(70 \%)$ & .0006 & 1.0 & .8273 & 0.9 & .2416 \\
\hline Q17 & Child has a dentist & $21(28 \%)$ & $61(35 \%)$ & $56(40 \%)$ & .2266 & 1.3 & .0200 & 1.0 & .4234 \\
\hline Q18 & Child has been to a dentist & $16(21 \%)$ & $49(28 \%)$ & $28(20 \%)$ & .2657 & 1.1 & .6861 & 0.9 & .5401 \\
\hline Q46 & Child to physician if only if in pain/sick & $7(9 \%)$ & $29(17 \%)$ & $28(20 \%)$ & .1369 & 0.9 & .5682 & 1.1 & .4226 \\
\hline Q74 & PCG has a dentist & $22(29 \%)$ & $92(53 \%)$ & $100(71 \%)$ & .0003 & 1.4 & .0062 & 1.2 & .0008 \\
\hline Q47 & PCG to dentist for regular checkups & $20(27 \%)$ & $74(42 \%)$ & $76(54 \%)$ & .0998 & 1.2 & .0674 & 1.2 & .0030 \\
\hline Q47 & PCG never to dentist & $29(39 \%)$ & $30(17 \%)$ & $15(11 \%)$ & .0047 & 0.6 & .0065 & 0.9 & .2742 \\
\hline Q48 & PCG to physician if only if in pain/sick & $31(41 \%)$ & $55(31 \%)$ & $78(55 \%)$ & .0001 & 1.2 & .2364 & 0.9 & .1303 \\
\hline Q48 & PCG to physician for regular checkups & $41(55 \%)$ & $132(75 \%)$ & $73(52 \%)$ & .0001 & 0.8 & .0776 & 1.2 & .0186 \\
\hline
\end{tabular}

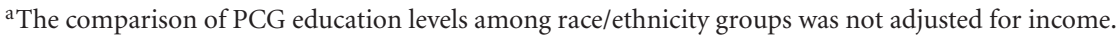

with the remaining caregivers consisting of 14 fathers, 2 grandmothers, 1 aunt, and 1 other. The caregivers' ages ranged from 18 to 64 years, with an average age of 28 (SD = 6) years. The children ranged in age from 16 to 36 months, with a mean of 26 (SD =6) months, and ages did not differ significantly by race/ethnicity, income, or education of the caregiver. $51 \%$ of the toddlers were female. One hundred seventy-five $(44 \%)$ of the caregivers self-identified themselves as Non-Hispanic African-American, 141 (36\%) were Non-Hispanic White, $75(19 \%)$ were Hispanic (all races), and $5(1 \%)$ did not fall into one of the previous three categories.

Nearly one-third of Hispanic caregivers reported difficulty understanding information they receive from physicians and dentists, while the rate was less than ten percent in Non-Hispanic African-Americans and Non-Hispanic Whites (Table 1). Concurrently, caregivers with less education also were more likely to report these difficulties. Furthermore, health literacy, collected on a subset of 250 caregivers, was not different among race/ethnicity groups but was weakly associated with education $(r=0.18, P=.02)$. NonHispanic Whites were more likely to use city water as their primary drinking water source as opposed to bottled or well water. Interestingly, drinking water source was not related to income or education in this cohort. There was a moderately high correlation between education and income $(r=0.56$, $P=.0001$ ) and moderate correlations for caregiver age with education $(r=0.42, P=.0001)$ and income $(r=0.38$, $P=.0001)$.

Habits of the caregivers that might lead to transmission of bacteria to the toddler differed by race/ethnicity (Figure 1), education, and income. Hispanic caregivers were less likely than Non-Hispanic African-American and NonHispanic White caregivers to put the toddler's pacifier in their own mouth $(12 \%$ versus $37 \%$ and $31 \%, P=.0156)$, which was also associated with higher education (odds ratio $1.3,95 \%$ CI $1.0-1.7, P=.0212$ ) but not with income (odds ratio $1.0,95 \%$ CI $0.8-1.1, P=.44$ ). Tasting the child's food or drink using the same fork/spoon or glass was common in all race/ethnicity groups (approximately $70 \%$, $P=.87$ ), but was more common with those reporting a higher income (odds ratio 1.3, 95\% CI 1.1-1.4, $P=.0013$ ). Sharing food with the child using the same bowl/plate/glass and kissing the child on the lips occurred with nearly all Non-Hispanic African-American and Non-Hispanic White caregivers but was less frequent among Hispanics $(P=$ .0001 ) and was more common with higher income (odds ratio $1.3,95 \%$ CI 1.1-1.6, $P=.0028$ ). However, $87 \%$ of Hispanics ever breast-fed compared to $50 \%$ of Non-Hispanic African-Americans and $62 \%$ of Non-Hispanic Whites $(P=$ .0004); breast-feeding was also more common with higher education (odds ratio 1.6, 95\% CI 1.2-2.1, $P=.0004$ ) and higher income (odds ratio $1.1,95 \%$ CI $1.0-1.3, P=$ .0458). 
TABLE 2: Relationships of race/ethnicity, education, and income with questionnaire responses for dental and medical health practices of the primary caregiver (PCG) and the toddler. Analyses were performed for each questionnaire item using multivariable logistic or linear regression models with race/ethnicity, income, and education as predictors. Race/ethnicity $P$-values are for the overall test of any difference among the three groups. Questionnaire item numbers are listed in the left-most column (see the appendix for questionnaire). $N(\%)$ or $\mathrm{Mean}(\mathrm{SD})$ for race/ethnicity, odds ratio $(\mathrm{OR})$ or correlation $(\mathrm{R})$ for education and income. NH-AA = Non-Hispanic African-American, NH-W = Non-Hispanic White.

\begin{tabular}{|c|c|c|c|c|c|c|c|c|c|}
\hline & & \multicolumn{4}{|c|}{ PCG Race/Ethnicity } & \multicolumn{2}{|c|}{ PCG Education } & \multicolumn{2}{|c|}{ PCG Income } \\
\hline & & $\begin{array}{l}\text { Hispanic } \\
(n=75)\end{array}$ & $\begin{array}{c}\text { NH-AA } \\
(n=175)\end{array}$ & $\begin{array}{c}\text { NH-W } \\
(n=141)\end{array}$ & $P$-value & $\mathrm{OR} / \mathrm{R}$ & $P$-value & $\mathrm{OR} / \mathrm{R}$ & $P$-value \\
\hline Q6 & PCG helps child brush & $71(95 \%)$ & $167(95 \%)$ & $128(91 \%)$ & .0649 & 1.2 & .5586 & 1.1 & .2882 \\
\hline Q8 & Child uses fluoride toothpaste & $34(45 \%)$ & $82(47 \%)$ & $62(44 \%)$ & .0846 & 0.9 & .5281 & 1.0 & .9273 \\
\hline Q9 & PCG checks child for cavities & $53(71 \%)$ & $85(49 \%)$ & $71(50 \%)$ & .0337 & 0.7 & .0046 & 0.9 & .4050 \\
\hline Q36 & Start Brush for 1st Tooth & $13(17 \%)$ & $46(26 \%)$ & $53(38 \%)$ & .0243 & 1.1 & .3197 & 1.0 & .6055 \\
\hline Q37 & Frequency of child's brushing ${ }^{\mathrm{a}}$ & $2.3(1.2)$ & $1.9(0.8)$ & $1.8(0.9)$ & .0055 & -0.09 & .9872 & -0.07 & .2822 \\
\hline Q38 & Frequency of PCG's brushing ${ }^{\mathrm{a}}$ & $1.3(0.5)$ & $1.5(0.7)$ & $1.4(0.6)$ & .0611 & -0.04 & .9771 & -0.10 & .2039 \\
\hline Q39 & Frequency of PCG's flossing ${ }^{\mathrm{a}}$ & $4.3(1.7)$ & $4.1(1.7)$ & $3.7(1.5)$ & .4248 & -0.25 & .0030 & -0.23 & .0731 \\
\hline Q49 & Child's dental health ${ }^{\mathrm{b}}$ & $2.8(1.1)$ & $2.1(1.0)$ & $2.0(0.9)$ & .0001 & -0.15 & .3530 & -0.12 & .4345 \\
\hline Q50 & Taking care of child's dental health ${ }^{\mathrm{b}}$ & $3.1(0.9)$ & $2.4(1.0)$ & $2.5(0.9)$ & .0001 & -0.01 & .2670 & 0.00 & .6502 \\
\hline Q51 & Child's medical health ${ }^{\mathrm{b}}$ & $2.1(0.9)$ & $1.6(0.8)$ & $1.7(0.7)$ & .0003 & -0.08 & .9636 & -0.07 & .2382 \\
\hline Q52 & Taking care of child's medical health ${ }^{\mathrm{b}}$ & $2.2(0.9)$ & $1.4(0.6)$ & $1.6(0.7)$ & .0001 & -0.12 & .3430 & -0.05 & .7470 \\
\hline Q53 & PCG's dental health ${ }^{\mathrm{b}}$ & $3.9(0.8)$ & $3.5(1.1)$ & $3.3(1.1)$ & .0906 & -0.32 & .0059 & -0.35 & .0001 \\
\hline Q54 & Taking care of own dental health ${ }^{\mathrm{b}}$ & $3.6(0.8)$ & $3.2(1.1)$ & $3.0(1.0)$ & .0285 & -0.15 & .1470 & -0.15 & .2572 \\
\hline Q55 & PCG's medical health ${ }^{\mathrm{b}}$ & $3.1(0.9)$ & $2.3(1.0)$ & $2.5(0.9)$ & .0001 & -0.17 & .0643 & -0.09 & .9939 \\
\hline Q56 & Taking care of own medical health ${ }^{\mathrm{b}}$ & $2.9(1.0)$ & $2.4(1.1)$ & $2.6(0.9)$ & .0033 & -0.05 & .4921 & -0.11 & .0357 \\
\hline Q69 & PCG often has dry mouth when eating & $10(13 \%)$ & $34(19 \%)$ & $23(16 \%)$ & .4116 & 0.9 & .3456 & 0.8 & .0137 \\
\hline Q70 & PCG has restorations for past cavities & $57(76 \%)$ & $118(67 \%)$ & $123(87 \%)$ & .0010 & 1.7 & .0008 & 1.0 & .6392 \\
\hline Q71 & PCG has current cavities & $42(56 \%)$ & $79(45 \%)$ & $47(33 \%)$ & .1029 & 0.8 & .0494 & 0.9 & .2353 \\
\hline Q72 & PCG bothered by how own teeth look & $46(61 \%)$ & $79(45 \%)$ & $57(40 \%)$ & .0309 & 0.9 & .3523 & 1.0 & .5640 \\
\hline Q73 & PCG needs dental treatment now & $64(85 \%)$ & $123(70 \%)$ & $78(55 \%)$ & .0009 & 0.9 & .3433 & 0.9 & .1089 \\
\hline Q75 & PCG scared of going to the dentist & $15(20 \%)$ & $50(29 \%)$ & $29(21 \%)$ & .0404 & 0.8 & .1557 & 1.0 & .9971 \\
\hline Q77 & PCG uses fluoride toothpaste & $56(75 \%)$ & $154(88 \%)$ & $118(84 \%)$ & .2974 & 1.2 & .2525 & 1.0 & .9745 \\
\hline
\end{tabular}

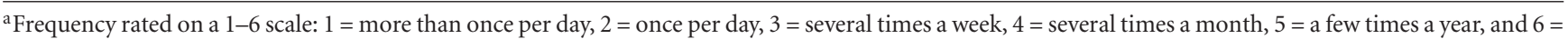
never.

${ }^{\mathrm{b}}$ Ratings on a $1-5$ scale: 1 = excellent, 2 = very good, $3=$ good, $4=$ fair, and $5=$ poor.

Although caregivers with more education more often reported that their child had a dentist (Table 2), there were no differences in whether the child had ever been to the dentist. Because the toddlers may have similar access to care as their caregivers, the questionnaire also asked about dentist and physician visits made by the caregiver. Seventy-one percent of Non-Hispanic White caregivers, 53\% of Non-Hispanic African-American caregivers, and 29\% of Hispanic caregivers had a dentist (Table 1), and having a dentist was also associated with higher education attainment and higher income. Approximately half of Non-Hispanic African-Americans caregivers reported going to the dentist for regular checkups, while nearly $40 \%$ of Hispanic caregivers reported never going to the dentist. Interestingly, higher income was associated with caregivers going to the dentist for checkups, while lower education but not income was associated with never going to the dentist. In addition, patterns of caregiver visits to the physician differed by race/ethnicity (Table 1) but were not as affected by income or education, where only regular visits to the physician were associated with higher income.

Hispanic caregivers reported their children's teeth were brushed less frequently than teeth of Non-Hispanic AfricanAmericans and Non-Hispanic Whites (Table 2). Caregivers with lower income were more likely to have problems with dry mouth when eating. Hispanic caregivers were more likely to be bothered by the appearance of their own teeth, which was not associated with education or income. Flossing was associated with more education but not with income or race/ethnicity. While there were differences among the race/ethnicity groups in how the caregivers felt about their child's and their own dental and medical health, education and income were generally not related to these ratings. Beliefs and knowledge (Figure 2) differed by race/ethnicity—adults eventually losing all their teeth $(P=.0001$, higher response of "false" for Non-Hispanic Whites), most children getting cavities ( $P=.0304$, lower response of "false" for Hispanics), bad teeth being mostly inherited from parents $(P=.0119$, 


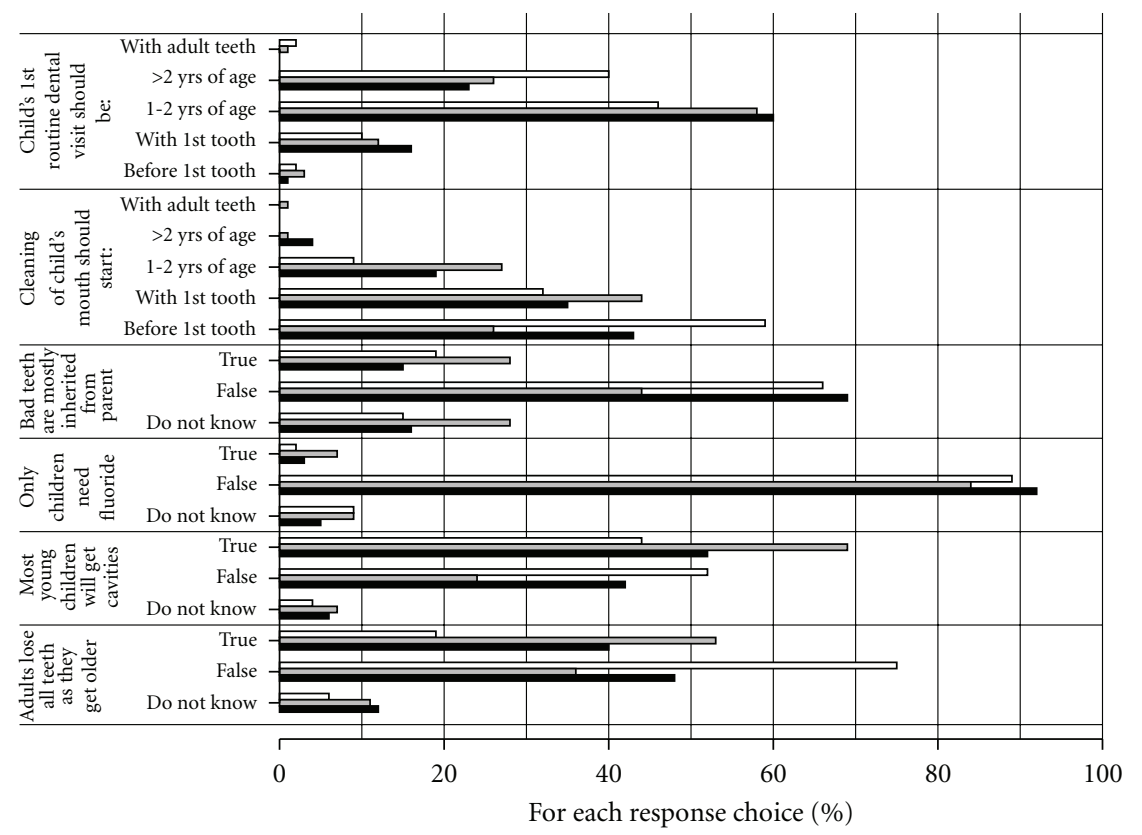

$\square$ Non-Hispanic African-American
$\square$ Hispanic
$\square$ Non-Hispanic White

FIGURE 2: Relationships of race/ethnicity with dental beliefs of caregivers. Analyses were performed for each questionnaire item using multivariable logistic regression models with race/ethnicity, income, and education as predictors. Differences among race/ethnicity groups were found for "cleaning should start" ( $P=.0001$, earlier for Non-Hispanic Whites), "bad teeth are mostly inherited from parent" $(P=.0119$, lower response of "false" for Hispanics), "most children will get cavities" $(P=.0304$, lower response of "false" for Hispanics), and "adults lose all teeth as they get older" ( $P=.0001$, higher response of "false" for Non-Hispanic Whites).

lower response of "false" for Hispanics), and when tooth cleaning should start $(P=.0001$, earlier for Non-HispanicWhites), with also a trend for when the child's first dental visit should be $(P=.06$, earliest for Non-Hispanic AfricanAmericans and latest for Non-Hispanic Whites). Belief that adults will eventually lose all their teeth was associated with less education (odds ratio $1.4,95 \%$ CI 1.1-1.8, $P=$ .0072 ) and lower income (odds ratio 1.1, 95\% CI 1.0-1.3, $P=$.0376), and belief that most children will eventually get cavities was associated with less education (odds ratio $1.3,95 \%$ CI 1.0-1.6, $P=.0258$ ), while none of the other beliefs/knowledge assessed were significantly associated with education or income.

Hispanic toddlers were more likely drink from a bottle (29\%) compared to Non-Hispanic Whites toddlers (11\%) and Non-Hispanic African-American toddlers (4\%), while Non-Hispanic White toddlers and Non-Hispanic AfricanAmerican toddlers were not significantly different. NonHispanic African-American toddlers were also less likely to drink from a sippy cup (67\%) compared to Non-Hispanic Whites $(84 \%)$ and Hispanic $(87 \%)$ toddlers, who were not significantly different from each other (Table 3 ). Hispanic children were most likely to receive a bottle or sippy cup at bedtime or naptime. Although Hispanic caregivers cleaned their child's teeth after removing the drink more frequently than Non-Hispanic African-Americans or Non-Hispanic Whites, cleaning the child's teeth after removing the drink was rare for all races. Less than half of Hispanic children regularly sipped on drinks between meals, while nearly all Non-Hispanic African-American and Non-Hispanic White children did. Types of snacks and drinks usually eaten/drank between meals varied considerably among race/ethnicity groups for toddlers (Table 3 ) and for PCGs (Table 4), while snacking and between-meals drinks were typically not associated with education or income, with a specific exception of nondiet soda being associated with less education.

\section{Discussion}

Despite a decrease in dental caries prevalence in permanent teeth for most Americans since the early 1970s, oral health disparities remain across some population groups, and dental caries is still the most prevalent chronic disease of childhood [1]. Furthermore, between 1988-1994 and 1999-2004, caries experience in primary teeth of children aged 2-5 years has significantly increased from $24 \%$ to $28 \%$, primarily due to an increase in the percent with fillings [45]. Unfortunately, as mentioned earlier, our current understanding of caries risk and etiological factors derived from longitudinal studies in young children in the United States is limited. Available caries risk questionnaire tools are, for the most part, expert-based tools. Examples include the Caries Risk Tool of the American Academy of Pediatric Dentistry [46], the ADA's Caries Risk Tool for children 
TABLE 3: Relationships of race/ethnicity, education, and income with questionnaire responses for snacking and drinking habits of the toddler. Analyses were performed for each questionnaire item using multivariable logistic or linear regression models with race/ethnicity, income, and education as predictors. Race/ethnicity $P$-values are for the overall test of any difference among the three groups. Questionnaire item numbers are listed in the left-most column (see the appendix for questionnaire). $N(\%)$ or Mean(SD) for race/ethnicity, odds ratio (OR) or correlation (R) for education and income. NH-AA = Non-Hispanic African-American, NH-W = Non-Hispanic White.

\begin{tabular}{|c|c|c|c|c|c|c|c|c|}
\hline & \multicolumn{4}{|c|}{ PCG Race/Ethnicity } & \multicolumn{2}{|c|}{ PCG Education } & \multicolumn{2}{|c|}{ PCG Income } \\
\hline & $\begin{array}{l}\text { Hispanic } \\
(n=75)\end{array}$ & $\begin{array}{l}\text { NH-AA } \\
(n=175)\end{array}$ & $\begin{array}{c}\text { NH-W } \\
(n=141)\end{array}$ & $P$-value & $\mathrm{OR} / \mathrm{R}$ & $P$-value & $\mathrm{OR} / \mathrm{R}$ & $P$-value \\
\hline Q1 Child usually drinks from a bottle & $22(29 \%)$ & $7(4 \%)$ & $15(11 \%)$ & .0001 & 1.1 & .2559 & 1.1 & .1013 \\
\hline Q2 Child usually drinks from a sippy cup & $65(87 \%)$ & $118(67 \%)$ & $118(84 \%)$ & .0001 & 0.6 & .0307 & 0.7 & .1374 \\
\hline Q40 Frequency of bottle/sippy at sleep time ${ }^{\mathrm{a}}$ & $2.9(2.1)$ & $4.5(2.0)$ & $4.4(2.0)$ & .0001 & 0.15 & .7376 & 0.16 & .0137 \\
\hline Q42 Brushing frequency after sleep-time drinks ${ }^{\mathrm{a}}$ & $4.6(2.0)$ & $5.9(1.6)$ & $5.7(1.9)$ & .0001 & 0.19 & .6731 & 0.19 & .0075 \\
\hline Q26 Child regularly sips drinks between meals & $32(43 \%)$ & $168(96 \%)$ & $129(91 \%)$ & .0001 & 0.8 & .1461 & 1.0 & .6605 \\
\hline Q31 Child usually snacks on candy & $31(41 \%)$ & $72(41 \%)$ & $36(26 \%)$ & .0557 & 0.8 & .1294 & 0.9 & .4255 \\
\hline Q31 Child usually snacks on cookies & $46(61 \%)$ & $104(59 \%)$ & $63(45 \%)$ & .0266 & 0.8 & .1237 & 1.0 & .6380 \\
\hline Q31 Child usually snacks on fresh fruit & $70(93 \%)$ & $145(83 \%)$ & $108(77 \%)$ & .0035 & 1.2 & .1935 & 1.1 & .2418 \\
\hline Q31 Child usually snacks on cake & $23(31 \%)$ & $35(20 \%)$ & $7(5 \%)$ & .0012 & 0.7 & .0480 & 0.9 & .6211 \\
\hline Q31 Child usually snacks on ice cream & $39(52 \%)$ & $47(27 \%)$ & $24(17 \%)$ & .0001 & 1.0 & .9244 & 0.9 & .3391 \\
\hline Q31 Child usually snacks on cereal with milk & $44(59 \%)$ & $93(53 \%)$ & $50(35 \%)$ & .0019 & 0.9 & .2473 & 1.0 & .6969 \\
\hline Q31 Child usually snacks on dried fruit & $22(29 \%)$ & $53(30 \%)$ & $45(32 \%)$ & .9827 & 1.0 & .8352 & 1.0 & .8686 \\
\hline Q31 Child usually snacks on popcorn & $27(36 \%)$ & $71(41 \%)$ & $52(37 \%)$ & .8911 & 1.1 & .8031 & 1.0 & .8911 \\
\hline Q31 Child usually snacks on chips & $45(60 \%)$ & $127(73 \%)$ & $65(46 \%)$ & .0001 & 0.9 & .5032 & 0.9 & .0442 \\
\hline Q31 Child usually snacks on dry cereal & $24(32 \%)$ & $103(59 \%)$ & $89(63 \%)$ & .0002 & 1.1 & .2060 & 1.0 & .8281 \\
\hline Q31 Child usually snacks on yogurt & $47(63 \%)$ & $59(34 \%)$ & $64(45 \%)$ & .0002 & 1.0 & .9864 & 1.2 & .0120 \\
\hline Q33 Child usually drinks water between meals & $65(87 \%)$ & $119(68 \%)$ & $98(70 \%)$ & .0028 & 1.1 & .3031 & 1.0 & .6363 \\
\hline Q33 Child usually drinks nondiet soda between meals & $22(29 \%)$ & $16(9 \%)$ & $14(10 \%)$ & .0038 & 0.7 & .0403 & 0.9 & .4546 \\
\hline Q33 Child usually drinks juice between meals & $67(89 \%)$ & $146(83 \%)$ & $98(70 \%)$ & .0012 & 1.0 & .6801 & 0.9 & .4027 \\
\hline Q33 Child usually drinks sugared fruit drink between meals & $46(61 \%)$ & $48(27 \%)$ & $31(22 \%)$ & .0001 & 0.8 & .0296 & 1.0 & .6489 \\
\hline Q33 Child usually drinks milk between meals & $63(84 \%)$ & $130(74 \%)$ & $109(77 \%)$ & .2159 & 1.2 & .2507 & 0.9 & .2117 \\
\hline Q44 Frequency child drinks tap water ${ }^{\mathrm{a}}$ & $3.2(2.3)$ & $2.6(1.9)$ & $1.8(1.5)$ & .0001 & -0.03 & .6840 & -0.02 & .8132 \\
\hline
\end{tabular}

${ }^{a}$ Frequency rated on a $1-6$ scale: $1=$ more than once per day, $2=$ once per day, $3=$ several times a week, $4=$ several times a month, $5=$ a few times a year, and $6=$ never.

younger than 6 [47], and the Caries Management by Risk Assessment (CAMBRA) tool for children younger than 6 $[48,49]$. While other studies have identified caries risk factors in low-SES rural [50] and low-SES African-American [30] communities, the prevalence of the risk factors may affect both the disease prevalence and the types of interventions that may be effective in preventing and/or treating caries. Age, socioeconomic status, and race/ethnicity differences as well as in non-US populations studied previously provided individual risk factor prevalence estimates, but only indirect evaluations of the effects of the sociodemographic factors on the risk factors could be made. In the present study, multiple factors from the caries risk questionnaire within the access to care, oral bacterial transmission, dental and medical health practices of the caregiver and the toddler, and snacking and drinking habits of the caregiver and the toddler areas were directly compared and differed by race/ethnicity, income, and/or education. Having general and pediatric dentists understand that these differences exist is only a first step. The information must be incorporated in improved strategies to treat and/or prevent caries in toddlers.
With the limited sample size and single location sampled in this study, it is difficult to differentiate the effects of cultural influences, health knowledge gained through educational background, and income-based health utilization disparities on the risk factors; in other words, we were unable to look at the influence of interactions among the three factors or stratify the analyses. And while the study included three race/ethnicity groups, the single location of the study (Indiana) may not fully represent responses nationwide. A larger multisite study would be needed for increased generalizability as well as provide the sample size needed to differentiate among the cultural, income, and education influences on the risk factors. A large number of risk factors were examined, based on the extensive list of factors proposed or identified previously. Some of the risk factors differing by sociodemographic factors are likely to be false positives. Nevertheless the information from our study can provide useful risk factor prevalence data when revising caregiver/patient education and preventive care intervention strategies. 
TABLE 4: Relationships of race/ethnicity, education, and income with questionnaire responses for snacking and drinking habits of the primary caregiver (PCG). Analyses were performed for each questionnaire item (items 80 through 82 - see the appendix for questionnaire) using multivariable logistic regression models with race/ethnicity, income, and education as predictors. Race/ethnicity $P$-values are for the overall test of any difference among the three groups. $N(\%)$ for Race/Ethnicity, Odds Ratio (OR) for education and income. NH-AA = Non-Hispanic African-American, NH-W = Non-Hispanic White.

\begin{tabular}{lcccccccc}
\hline & & \multicolumn{2}{c}{ PCG race/ethnicity } & \multicolumn{3}{c}{ PCG education } \\
& $\begin{array}{c}\text { Hispanic } \\
(n=75)\end{array}$ & $\begin{array}{c}\text { NH-AA } \\
(n=175)\end{array}$ & $\begin{array}{c}\text { NH-W } \\
(n=141)\end{array}$ & $P$-value & OR & $P$-value & OR & $P$-value \\
\hline PCG has snacks on most days & $48(64 \%)$ & $143(82 \%)$ & $108(77 \%)$ & .0314 & 1.4 & .0144 & 1.1 & .3236 \\
PCG usually snacks on candy & $16(21 \%)$ & $77(44 \%)$ & $37(26 \%)$ & .0001 & 0.9 & .4449 & 1.0 & .7326 \\
PCG usually snacks on cookies & $27(36 \%)$ & $81(46 \%)$ & $49(35 \%)$ & .0140 & 1.0 & .7664 & 1.1 & .4027 \\
PCG usually snacks on fresh fruit & $46(61 \%)$ & $98(56 \%)$ & $69(49 \%)$ & .1863 & 1.2 & .0874 & 1.0 & .4175 \\
PCG usually snacks on cake & $21(28 \%)$ & $52(30 \%)$ & $13(9 \%)$ & .0002 & 0.9 & .5992 & 1.0 & .8133 \\
PCG usually snacks on ice cream & $25(33 \%)$ & $59(34 \%)$ & $28(20 \%)$ & .0143 & 1.1 & .7390 & 1.0 & .5263 \\
PCG usually snacks on popcorn & $15(20 \%)$ & $73(42 \%)$ & $47(33 \%)$ & .0111 & 1.1 & .3649 & 1.1 & .0372 \\
PCG usually snacks on chips & $24(32 \%)$ & $118(67 \%)$ & $57(40 \%)$ & .0001 & 1.1 & .5857 & 1.0 & .7557 \\
PCG usually drinks water between meals & $69(92 \%)$ & $135(77 \%)$ & $98(70 \%)$ & .0003 & 1.2 & .3087 & 1.1 & .0777 \\
PCG usually drinks nondiet soda between meals & $28(37 \%)$ & $94(54 \%)$ & $62(44 \%)$ & .0186 & 0.7 & .0105 & 1.0 & .4225 \\
PCG usually drinks diet soda between meals & $11(15 \%)$ & $18(10 \%)$ & $27(19 \%)$ & .2055 & 1.4 & .0381 & 1.1 & .2771 \\
PCG usually drinks juice between meals & $44(59 \%)$ & $89(51 \%)$ & $31(22 \%)$ & .0001 & 0.8 & .0771 & 1.0 & .4755 \\
PCG usually drinks sugared fruit drink & $36(48 \%)$ & $45(26 \%)$ & $17(12 \%)$ & .0001 & 0.9 & .8146 & 0.9 & .3596 \\
PCG usually drinks milk between meals & $35(47 \%)$ & $41(23 \%)$ & $40(28 \%)$ & .0054 & 0.9 & .4149 & 0.9 & .1142 \\
PCG usually drinks tea between meals & $8(11 \%)$ & $32(18 \%)$ & $45(32 \%)$ & .0006 & 1.0 & .7849 & 0.9 & .2744 \\
PCG usually drinks coffee w/sugar between meals & $21(28 \%)$ & $12(7 \%)$ & $13(9 \%)$ & .0001 & 0.9 & .5356 & 1.1 & .3277 \\
\hline
\end{tabular}

As mentioned above, our sample size was not large enough to justify a detailed examination of the 3-way interaction among race/ethnicity, income, and education to differentiate the effects of cultural influences, health knowledge gained through educational background, and income-based health utilization disparities on the risk factors. Regardless of the underlying "cause", as others have suggested based on observations in various populations $[32,36]$, education and intervention strategies can be targeted generally to the population seen in the practice and specifically to individual patients. It is noteworthy to mention efforts in this country by medical (e.g., American Academy of Pediatrics and American Medical Association [51, 52]) and dental (e.g., American Dental Association [47], American Academy of Pediatric Dentistry [46, 53]) associations, among others, to stress not only the importance of a dental home early in life, but also the importance of riskbased preventive interventions and anticipatory guidance provided in a variety of settings to reach young children. In fact, a variety of programs have evolved in different places around the country. The "Into the Mouth of Babes" (IBM) program in North Carolina is one of the best examples of the effort resulting from the partnership between dentists and pediatricians to improve the oral health of children. The IMB program was initiated in 2000 and has led to a substantial increase in access to preventive dental services by enabling Medicaid children younger than 3 years of age to receive dental screening, counseling, and fluoride varnish in physicians' offices [54]. More work will certainly be needed to evaluate the acceptability and effectiveness of education and intervention strategies in targeted populations.

One problem hindering treatment and prevention of caries in high-risk children is that they may not seek care from dentists regularly, if at all. Despite the importance of establishing a "dental home" in the first year of life, most children do not receive a dental examination, nor do the parents receive needed education on oral health [55]. This is especially true for those at the highest risk. While $89 \%$ of infants and one-year-olds have been examined by a physician, only $1.5 \%$ has had a dental appointment [53]. Some of the factors identified above could be included in discussions of "healthy behaviors" with the caregivers at wellchild checkups. Patient education materials could also be developed to be made available through pediatrician and family practice offices. The results from our study may be useful to future investigators to focus the materials on factors prevalent in specific offices, such transmission of bacteria through sharing drinks or foods in higher income practices and providing drinks at bedtime or naptime in offices that have a high proportion of Hispanics.

In conclusion, significant differences were found in all areas of the questionnaire related to race/ethnicity, income, and/or education. A larger followup study may be able to explore more detailed differentiation of the effects of cultural influences, health knowledge gained through educational background, and income-based health utilization disparities on the risk factors. Patient education and preventive care intervention studies may need to be targeted based on 
the characteristics of the population to achieve increase effectiveness.

\section{Appendix}

\section{Questionnaire}

First, I'd like to ask about the child's (i.e., refers to the child in this study) eating and health habits. Please answer yes or no for each of the following questions.

(1) Does the child usually drink from a bottle?

Yes

No

(2) Does the child usually drink from a sippy cup?

$$
\text { Yes }
$$

No

(3) Is the child currently being breast-fed?

$$
\text { Yes }
$$$$
\text { No }
$$

(4) If not currently breast-fed, was the child ever breastfed? (if yes, how long was the child breastfeed for: ...... months)

$$
\text { Yes }
$$

No

(5) Does the child share a toothbrush with anyone? (if yes, indicate who:

$$
\text { Yes }
$$

No

Does not use one

(6) Do you help the child brush his or her teeth?

$$
\text { Yes }
$$

No

(7) When you or the child brushes his/her teeth, do you use toothpaste?

$$
\begin{aligned}
& \text { Yes } \\
& \text { No }
\end{aligned}
$$

(8) Does the child's toothpaste have fluoride in it?

$$
\begin{aligned}
& \text { Yes } \\
& \text { No } \\
& \text { Do not know }
\end{aligned}
$$

(9) Do you ever check the child's teeth for cavities?

$$
\text { Yes }
$$

No
(10) Does the child have cavities now?

$$
\begin{aligned}
& \text { Yes } \\
& \text { No } \\
& \text { Do not know }
\end{aligned}
$$

(11) Has the child had cavities or fillings in the past?

$$
\begin{aligned}
& \text { Yes } \\
& \text { No }
\end{aligned}
$$

(12) Has the child had teeth pulled because of cavities?

$$
\begin{aligned}
& \text { Yes } \\
& \text { No }
\end{aligned}
$$

(13) Have other children (brothers, sisters, or others) in the child's household had cavities or fillings?

$$
\begin{aligned}
& \text { Yes } \\
& \text { No } \\
& \text { Only child }
\end{aligned}
$$

(14) Does the child have problems chewing?

$$
\begin{aligned}
& \text { Yes } \\
& \text { No }
\end{aligned}
$$

(15) Does the child have a tooth that hurts?

$$
\text { Yes }
$$

No

(16) Do you think the child is bothered about how his/her teeth look?

$$
\text { Yes }
$$

No

(17) Does the child have a dentist?

$$
\begin{aligned}
& \text { Yes } \\
& \text { No }
\end{aligned}
$$

(18) Has the child ever been to the dentist?

$$
\text { Yes }
$$

No

(19) Does the child use other products for his/her teeth (mouth rinse, prescription toothpaste, tablets, drops, or other) with fluoride? (do not count water)

$$
\begin{aligned}
& \text { Yes } \\
& \text { No } \\
& \text { Do not know }
\end{aligned}
$$

(20) Do or did you ever put the child's pacifier in your mouth before giving it to him/her? 


$$
\text { Yes }
$$$$
\text { No }
$$

Does not use it

(21) Do you ever kiss the child on the lips?

$$
\begin{aligned}
& \text { Yes } \\
& \text { No }
\end{aligned}
$$

(22) When the child was born, were you told by his/her doctor that his/her birth-weight was low?

$$
\text { Yes }
$$$$
\text { No }
$$

Do not know

(23) Did the child's mother get prenatal care?

$$
\begin{aligned}
& \text { Yes } \\
& \text { No } \\
& \text { Do not know }
\end{aligned}
$$

(24) Do you ever taste the child's food and/or drinks using the same spoon, fork, glass, or other?

$$
\begin{aligned}
& \text { Yes } \\
& \text { No }
\end{aligned}
$$

(25) Do you ever share food or drinks with the child from the same plate, bowl, or glass?

$$
\begin{aligned}
& \text { Yes } \\
& \text { No }
\end{aligned}
$$

(26) Does the child regularly sip on drinks between meals on most days?

$$
\text { Yes }
$$$$
\text { No }
$$

(27) Does the child use antibiotics more than every three months?

$$
\begin{aligned}
& \text { Yes } \\
& \text { No }
\end{aligned}
$$

(28) Does the child regularly use medications at bedtime or during the night?

$$
\begin{aligned}
& \text { Yes } \\
& \text { No (skip to no. 30) }
\end{aligned}
$$

(29) Do you regularly brush the child's teeth after use of the medication?

$$
\begin{aligned}
& \text { Yes } \\
& \text { No }
\end{aligned}
$$

(30) Does the child have snacks most days?
Yes

No (skip to no. 32)

(31) What kinds of foods does he/she usually snack on? (A snack is food eaten in between regular meals.) Please read the list, and check all foods that apply.

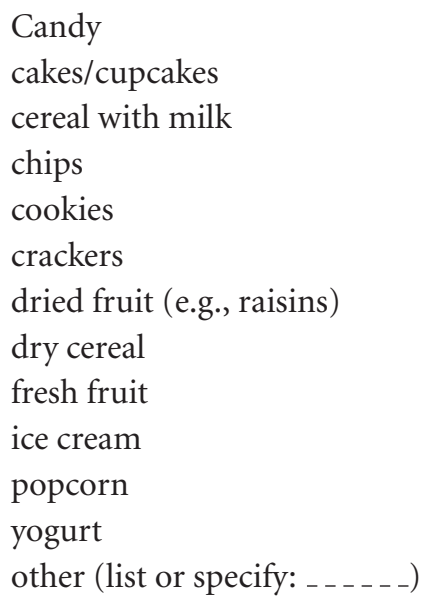

(32) How many regular meals (e.g., breakfast, lunch, dinner, or other) does the child eat per day?

(33) What does he/she usually drink with a snack or in between meals? Please read the list, and check all drinks that apply.

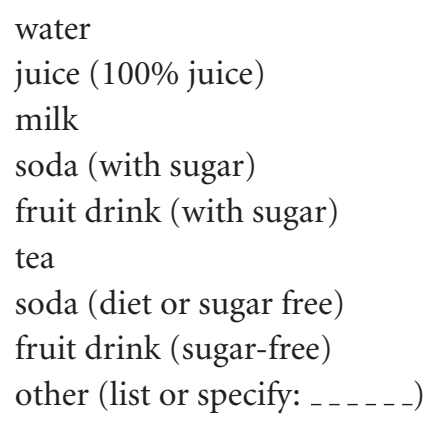

(34) The child's main source of drinking water is:

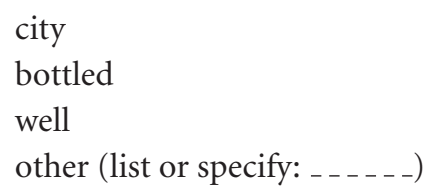

(35) The child got his/her first tooth at _... _ months of age.

(36) When did brushing/cleaning of the child's teeth start? (check all that apply)

when the first tooth came into the mouth younger than 12 months

13-24 months

25-36 months

older than 36 months

not brushing/cleaning teeth yet 
(37) How often do you or the child clean or brush the child's teeth? Would you say...

More than once a day

Once a day

Several times a week

Several times a month

A few times a year

Never

(38) How often do you brush your own teeth?

More than once a day

Once a day

Several times a week

Several times a month

A few times a year

Never

(39) How often do you floss your own teeth?

More than once a day

Once a day

Several times a week

Several times a month

A few times a year

Never

(40) How often does the child get a bottle/sippy cup in bed, at either bedtime or naptime with something other than water in it?

More than once a day

Once a day

Several times a week

Several times a month

A few times a year

Never

(41) How often does the child get a bottle/sippy cup filled with something other than water in it during the day (do not count mealtimes)?

More than once a day

Once a day

Several times a week

Several times a month

A few times a year

Never

(42) How often do you clean your child's teeth after you remove the bottle/sippy cup at night (after going to bed)?

More than once a day

Once a day
Several times a week

Several times a month

A few times a year

Never

Does not drink at night

(43) How often does your child breast-feed at night?

More than once a day

Once a day

Several times a week

Several times a month

A few times a year

Never

Does not breast-feed

(44) How frequently does your child drink tap water or drinks prepared with tap water?

More than once a day

Once a day

Several times a week

Several times a month

A few times a year

Never

(45) Which sentence or sentences below describe how you decide (or intend to decide) when to take the child to the dentist? (check all that apply)

I only take the child to the dentist if he/she has pain or a problem with his/her teeth.

I take the child to the dentist regularly because he/she has problems with the teeth or gums.

I take the child to the dentist for regular checkups.

I do not take the child to the dentist as often as the dentist wants me to.

I never take the child to the dentist.

(46) Which sentence or sentences below describe how you decide when to take the child to the doctor? (check all that apply)

I only take the child to the doctor if he/she has pain or is sick.

I take the child to the doctor regularly because he/she has a health problem.

I take the child to the doctor for regular checkups.

I don't take the child to the doctor as often as the doctor wants me to.

I never take the child to the doctor.

(47) Which sentence or sentences below describe how you decide when to see your dentist? (check all that apply). 
I only go to the dentist if I have pain or if I have a problem with my teeth or gums.

I see my dentist regularly because I have problems with my teeth or gums.

I see my dentist for regular checkups.

I don't see my dentist as often as the dentist wants me to.

I never go to the dentist.

(48) Which sentence or sentences below describe how you decide when to see your doctor? (check all that apply)

I only go to the doctor if I have pain or if I'm sick.

I see my doctor regularly because of a health problem.

I see my doctor for regular checkups.

I don't see my doctor as often as the doctor wants me to.

I never go to the doctor.

(49) How would you describe the child's dental (teeth and gums) health? Would you say it is...

Excellent

Very good

Good

Fair

Poor

(50) How would you describe how you take care of the child's dental (teeth and gums) health?

Excellent

Very good

Good

Fair

Poor

(51) How would you describe the child's medical health?

Excellent

Very good

Good

Fair

Poor

(52) How would you describe how you take care of the child's medical health?

Excellent

Very good

Good

Fair

Poor
(53) How would you describe your dental (teeth and gums) health?
Excellent
Very good
Good
Fair
Poor

(54) How would you describe how you take care of your dental (teeth and gums) health?

Excellent

Very good

Good

Fair

Poor

(55) How would you describe your medical health?
Excellent
Very good
Good
Fair
Poor

(56) How would you describe how you take care of your medical health?

Excellent

Very good

Good

Fair

Poor

(57) How satisfied are you with the child's dentist/dental care?

Very Satisfied

Somewhat Satisfied

Somewhat Dissatisfied

Very Dissatisfied

Not Applicable

(58) How satisfied are you with the child's doctor/medical care?

Very Satisfied

Somewhat Satisfied

Somewhat Dissatisfied

Very Dissatisfied

Not Applicable

(59) How satisfied are you with your dentist/dental care?

Very Satisfied

Somewhat Satisfied 
Somewhat Dissatisfied

Very Dissatisfied

Not Applicable

(60) How satisfied are you with your doctor/medical care?

Very Satisfied

Somewhat Satisfied

Somewhat Dissatisfied

Very Dissatisfied

Not Applicable

The next questions focus on your dental beliefs. Please answer True or False to the following statements.

(61) Most adults will lose all their teeth as they get older

True

False

Do not know

(62) Most young children will get cavities

True

False

Do not know

(63) Only children need fluoride

True

False

Do not know

(64) The type of food and drink a child eats or drinks may cause cavities

True

False

Do not know

(65) Baby teeth are important to take care of

True

False

Do not know

(66) Bad teeth are mostly inherited from the parents

True

False

Do not know

(67) Cleaning of the mouth of a child should begin: (check all that apply)

before the first tooth comes in as soon as the first tooth comes in 12-24 months-of-age after 24 months-of-age

when the adult teeth come in

do not know

(68) A child's first routine dental visit should be: (check all that apply)

before the first tooth comes in

as soon as the first tooth comes in

12-24 months-of-age

after 24 months-of-age

when the adult teeth come in

do not know habits.

The next questions focus on your own eating and health

(69) Does your mouth often feel dry when you eat a meal?

Yes

No

(70) Have you had any cavities in the past, which are now restored/fixed?

Yes

No

(71) Do you have cavities now that are not "fixed"?

Yes

No

Do not know

(72) Are you bothered by how your teeth look?

Yes

No

(73) Do you think you need dental treatment (other than a cleaning) now?

Yes

No

(74) Do you have a dentist?

Yes

No

(75) Are you scared of going to the dentist?

Yes

No

(76) When you brush your teeth, do you use toothpaste?

Yes

No 
(77) Does the toothpaste you use have fluoride in it?

$$
\begin{aligned}
& \text { Yes } \\
& \text { No } \\
& \text { Do not know }
\end{aligned}
$$

(78) Do you use other products for your teeth (mouth rinse, prescription toothpaste, other) with fluoride?

$$
\text { Yes }
$$$$
\text { No }
$$

Do not know

(79) Have you had more than half of your adult teeth pulled?

$$
\text { Yes }
$$$$
\text { No }
$$

(80) Do you have snacks most days?

$$
\text { Yes }
$$

No (skip to no. 82)

(81) What kinds of foods do you usually snack on? (A snack is food eaten in between regular meals.) Please read the list, and check all foods that apply.

candy

cakes/cupcakes

cereal with milk

chips

cookies

crackers

dried fruit (e.g., raisins)

dry cereal

fresh fruit

ice cream

popcorn

yogurt

other (list or specify:

(82) What do you usually drink with a snack or in between meals? Please read the list, and check all drinks that apply.

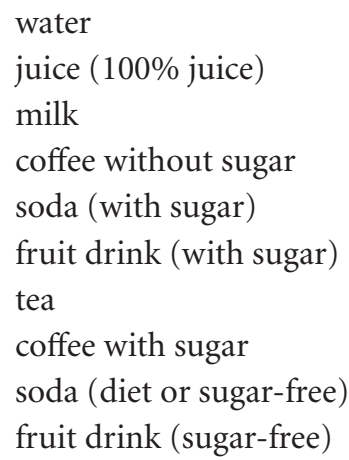

$$
\text { other (list or specify _-_-_-_) }
$$

Now we are going to ask some questions about you, the child's family, and the child.

(83) What is the highest grade in school you have completed?

$$
\begin{aligned}
& \text { Grade school }(1,2,3,4,5,6,7,8) \\
& \text { High school }(9,10,11,12) \\
& \text { College }(13,14,15,16) \\
& \text { Post graduate }(17+)
\end{aligned}
$$

(84) Does the child have Medicaid or Hoosier Healthwise?

$$
\begin{aligned}
& \text { Yes } \\
& \text { No }
\end{aligned}
$$

(85) Does the child have health insurance? (Private Health insurance)

$$
\text { Yes }
$$$$
\text { No }
$$

(86) Does the child receive free care (medical or dental) through any other program?

$$
\begin{aligned}
& \text { Yes } \\
& \text { No }
\end{aligned}
$$

(87) Do you have health insurance?

Yes

No

(88) Do you have dental insurance?

Yes

No

(89) In what country were you born?

U.S.

Another country List:

(90) In what country was the child born?

U.S. (skip to 92)

Another country List: _. _. _. -

(91) How long has the child been in the United States? Remember, all information you give us is confidential.

$$
\text { - - - - - - years }
$$

(92) What language do you usually speak at home?

English

Another language List: _. - _. - - 
(93) Because of language, do you have difficulty talking to the child's dentist or doctor?

$$
\text { Yes }
$$$$
\text { No }
$$

Regularly use an interpreter

(94) Is it sometimes difficult for you to understand the information given by the child's doctor or dentist?

$$
\begin{aligned}
& \text { Yes } \\
& \text { No }
\end{aligned}
$$

(95) Do you consider the child to be Spanish, Hispanic, or Latino?

$$
\text { Yes }
$$$$
\text { No }
$$

(96) Do you consider yourself to be Spanish, Hispanic, or Latino?

$$
\text { Yes }
$$$$
\text { No }
$$

(97) What is the child's racial or ethnic background? (Mark one or more races to indicate the race or races you consider the child to be)

\section{White or Caucasian}

African American or Black (Black refers to people with ancestors from Sub-Saharan Africa, the West Indies, the Caribbean (including Haiti, Jamaica, Barbados, and Cape Verde)

Asian (specify subgroup

Native Hawaiian or other Pacific Islander

American Indian or Alaskan Native

Other (specify: _._._- $)$

(98) What is your racial or ethnic background? (Mark one or more races to indicate the race or races you consider yourself to be)

White or Caucasian

African American or Black (Black refers to people with ancestors from Sub-Saharan Africa, the West Indies, the Caribbean (including Haiti, Jamaica, Barbados, and Cape Verde)

Asian (specify subgroup _ _ _ _ _ _)

Native Hawaiian or other Pacific Islander

American Indian or Alaskan Native

Other (specify: _._._._.

(99) How many adults live in the child's household?

Number of Adults/Children _.....

(100) How many adults in the child's household have paid jobs?
Number of Adults/Children

(101) How many adults other than yourself take care of the child regularly?

$$
\text { Number of Adults/Children _..... - }
$$

(102) How many children live in the child's household, including the study child?

$$
\text { Number of Adults/Children _. . . - - }
$$

(103) Do you have a job?

$$
\begin{aligned}
& \text { Yes } \\
& \text { No }
\end{aligned}
$$

(104) Do you have transportation to go to the doctor or dentist?

Yes

(105) Which of the following categories best represents the combined income for all family members in your household added together for the past 12 months? (Remember, all information is completely confidential). Please read the list of income categories and check the one that applies to you.

$$
\begin{aligned}
& \text { Less than } \$ 5000 \\
& \$ 5,000-\$ 9,999 \\
& \$ 10,000-\$ 19,999 \\
& \$ 20,000-\$ 29,999 \\
& \$ 30,000-\$ 39,999 \\
& \$ 40,000-\$ 49,999 \\
& \$ 50,000-\$ 79,999 \\
& \$ 80,000-\$ 99,999 \\
& \$ 100,000 \text { or more } \\
& \text { Do not know }
\end{aligned}
$$

\section{Acknowledgments}

This study was supported by NIH 1 R21 DE016451-01 and NIH RO3 DE017090-01. The authors would like to thank the following individuals for their assistance in questionnaire development: Masatoshi Ando, James Bader, Brian Burt, Judith Chin, Gustavo Cruz, Stephen Downs, Andrea Ferreira Zandona, Raul Garcia, Catherine Hayes, Amid Ismail, Steve Levy, Daniel Shugars, George Stookey, Nancy Swigonski, Carlos Ugarte, John Warren, James Wefel, Julie Meek, Phil Weinstein, and Dominick Zero. 


\section{References}

[1] US Department of Health and Human Services, Oral Health in America: A Report of the Surgeon General-Executive Summary, US Department of Health and Human Services, National Institute of Dental and Craniofacial Research, National Institutes of Health, Rockville, Md, USA, 2000.

[2] L. M. Kaste, R. H. Selwitz, R. J. Oldakowski, J. A. Brunelle, D. M. Winn, and L. J. Brown, "Coronal caries in the primary and permanent dentition of children and adolescents $1-17$ years of age: United States, 1988-1991," Journal of Dental Research, vol. 75, pp. 631-641, 1996.

[3] C. M. Vargas, J. J. Crall, and D. A. Schneider, "Sociodemographic distribution of pediatric dental caries: NHANES III, 1988-1994," Journal of the American Dental Association, vol. 129, no. 9, pp. 1229-1238, 1998.

[4] M. Anderson, "Risk assessment and epidemiology of dental caries: review of the literature," Pediatric Dentistry, vol. 24, no. 5, pp. 377-385, 2002.

[5] S. C. Scrimshaw, "Our multicultural society: implications for pediatric dental practice. Keynote speaker, 17th annual symposium, Denver, Colorado, Saturday, May 25, 2002," Pediatric Dentistry, vol. 25, no. 1, pp. 11-15, 2003.

[6] J. D. Featherstone, "The caries balance: contributing factors and early detection," Journal of the California Dental Association, vol. 31, no. 2, pp. 129-133, 2003.

[7] R. E. Stewart and K. J. Hale, "The paradigm shift in the etiology, prevention, and management of dental caries: its effect on the practice of clinical dentistry," Journal of the California Dental Association, vol. 31, no. 3, pp. 247-251, 2003.

[8] M. Fontana and D. T. Zero, "Assessing patients' caries risk," Journal of the American Dental Association, vol. 137, no. 9, pp. 1231-1239, 2006.

[9] D. Zero, M. Fontana, and A. M. Lennon, "Clinical applications and outcomes of using indicators of risk in caries management," Journal of Dental Education, vol. 65, no. 10, pp. 1126$1132,2001$.

[10] S. Twetman and M. Fontana, "Patient caries risk assessment," Monographs in Oral Science, vol. 21, pp. 91-101, 2009.

[11] Development Conference Statement, "Diagnosis and management of dental caries throughout life. National Institutes of Health Consensus Development Conference statement, March 26-28, 2001," Journal of Dental Education, vol. 65, no. 10, pp. $1162-1168,2001$.

[12] P. W. Caufield, K. Ratanapridakul, D. N. Allen, and G. R. Cutter, "Plasmid-containing strains of Streptococcus mutans cluster within family and racial cohorts: implications for natural transmission," Infection and Immunity, vol. 56, no. 12, pp. 3216-3220, 1988.

[13] O. Fejerskov, et al., "Changing paradigms in concepts on dental caries: consequences for oral health care," Caries Research, vol. 38, no. 3, pp. 182-191, 2004.

[14] J. D. B. Featherstone, "The science and practice of caries prevention," Journal of the American Dental Association, vol. 131, no. 7, pp. 887-899, 2000.

[15] Y. Li and P. W. Caufield, "The fidelity of initial acquisition of mutans streptococci by infants from their mothers," Journal of Dental Research, vol. 74, no. 2, pp. 681-685, 1995.

[16] N. L. Huntington, I. J. Kim, and C. V. Hughes, "Cariesrisk factors for Hispanic children affected by early childhood caries," Pediatric Dentistry, vol. 24, no. 6, pp. 536-542, 2002.

[17] H. A. B. Linke, E. O. Kuyinu, B. Ogundare et al., "Microbiological composition of whole saliva and caries experience in minority populations," Dental Clinics of North America, vol. 47 , no. 1 , pp. $67-85,2003$
[18] M. W. Ng, "Multicultural influences on child-rearing practices: implications for today's pediatric dentist," Pediatric Dentistry, vol. 25, no. 1, pp. 19-22, 2003.

[19] C. Okunseri, V. Badner, J. Kumar, and G. D. Cruz, "Dental caries prevalence and treatment need among racial/ethnic minority schoolchildren," The New York State Dental Journal, vol. 68, no. 8, pp. 20-23, 2002.

[20] I. C. Punwani, "Our multicultural society: implications for pediatric dental practice," Pediatric Dentistry, vol. 25, no. 1, pp. 9-10, 2003.

[21] C. H. Shiboski, S. A. Gansky, F. Ramos-Gomez, L. Ngo, R. Isman, and H. F. Pollick, "The association of early childhood caries and race/ethnicity among California preschool children," Journal of Public Health Dentistry, vol. 63, no. 1, pp. 3846, 2003.

[22] SBU: The Swedish Council on Technology Assessment in Health Care, "Caries-diagnosis, risk assessment and noninvasive treatment. A systematic review. Summary and conclusions," Tech. Rep. 188, 2007.

[23] M. Demers, J. M. Brodeur, C. Mouton, P. L. Simard, L. Trahan, and G. Veilleux, "A multivariate model to predict caries increment in Montreal children aged 5 years," Community Dental Health, vol. 9, no. 3, pp. 273-281, 1992.

[24] M. Grindefjord, G. Dahllöf, B. Nilsson, and T. Modéer, "Prediction of dental caries development in 1-year-old children," Caries Research, vol. 29, no. 5, pp. 343-348, 1995.

[25] M. Grindefjord, G. Dahllöf, B. Nilsson, and T. Modéer, "Stepwise prediction of dental caries in children up to 3.5 years of age," Caries Research, vol. 30, no. 4, pp. 256-266, 1996.

[26] S. Karjalainen, E. Söderling, L. Sewón, H. Lapinleimu, and O. Simell, "A prospective study on sucrose consumption, visible plaque and caries in children from 3 to 6 years of age," Community Dentistry and Oral Epidemiology, vol. 29, no. 2, pp. 136-142, 2001.

[27] K. Pienihäkkinen and J. Jokela, "Clinical outcomes of riskbased caries prevention in preschool-aged children," Community Dentistry and Oral Epidemiology, vol. 30, no. 2, pp. 143$150,2002$.

[28] K. Pienihäkkinen, J. Jokela, and P. Alanen, "Assessment of Caries Risk in Preschool Children," Caries Research, vol. 38, no. 2, pp. 156-162, 2004

[29] L.-K. Wendt, A.-L. Hallonsten, G. Koch, and D. Birkhed, "Analysis of caries-related factors in infants and toddlers living in Sweden," Acta Odontologica Scandinavica, vol. 54, no. 2, pp. 131-137, 1996.

[30] A. I. Ismail, W. Sohn, S. Lim, and J. M. Willem, "Predictors of dental caries progression in primary teeth," Journal of Dental Research, vol. 88, no. 3, pp. 270-275, 2009.

[31] X.-L. Gao, C.-Y. S. Hsu, Y. Xu, H. B. Hwarng, T. Loh, and D. Koh, "Building caries risk assessment models for children," Journal of Dental Research, vol. 89, no. 6, pp. 637-643, 2010.

[32] T. L. Finlayson, K. Siefert, A. I. Ismail, and W. Sohn, "Psychosocial factors and early childhood caries among lowincome African-American children in Detroit," Community Dentistry and Oral Epidemiology, vol. 35, no. 6, pp. 439-448, 2007.

[33] S. Doméjean-Orliaguet, S. A. Gansky, and J. D. Featherstone, "Caries risk assessment in an educational environment," Journal of Dental Education, vol. 70, no. 12, pp. 1346-1354, 2006.

[34] K. H. Abrahamsson, M. Hakeberg, J. Stenman, and K. Öhrn, "Dental beliefs: evaluation of the Swedish version of the revised Dental Beliefs Survey in different patient groups and in a non-clinical student sample," European Journal of Oral Sciences, vol. 114, no. 3, pp. 209-215, 2006. 
[35] J. L. Riley III, G. H. Gilbert, and M. W. Heft, "Dental attitudes: proximal basis for oral health disparities in adults," Community Dentistry and Oral Epidemiology, vol. 34, no. 4, pp. 289-298, 2006.

[36] L. M. López del Valle, C. A. Riedy, and P. Weinstein, "Rural Puerto Rican women's views on children's oral health: a qualitative community-based study," Journal of Dentistry for Children, vol. 72, no. 2, pp. 61-66, 2005.

[37] K. Arnrup, U. Berggren, and A. G. Broberg, "Usefulness of a psychometric questionnaire in exploring parental attitudes in children's dental care," Acta Odontologica Scandinavica, vol. 59, no. 1, pp. 14-20, 2001.

[38] S. Y. L. Kwan and S. A. Williams, "Dental beliefs, knowledge and behaviour of Chinese people in the United Kingdom," Community Dental Health, vol. 16, no. 1, pp. 33-39, 1999.

[39] J. G. Steele, A. W. G. Walls, S. M. T. Ayatollahi, and J. J. Murray, "Dental attitudes and behaviour among a sample of dentate older adults from three English communities," British Dental Journal, vol. 180, no. 4, pp. 131-136, 1996.

[40] G. H. Gilbert, R. P. Duncan, M. W. Heft, and R. T. Coward, "Dental health attitudes among dentate black and white adults," Medical Care, vol. 35, no. 3, pp. 255-271, 1997.

[41] N. J. Williams, J. G. Whittle, and A. C. Gatrell, "The relationship between socio-demographic characteristics and dental health knowledge and attitudes of parents with young children," British Dental Journal, vol. 193, no. 11, pp. 651-654, 2002.

[42] C. P. Saunders and G. J. Roberts, "Dental attitudes, knowledge, and health practices of parents of children with congenital heart disease," Archives of Disease in Childhood, vol. 76, no. 6, pp. 539-540, 1997.

[43] Y. Kawashita, H. Fukuda, K. Kawasaki et al., "Dental caries in 3-year-old children is associated more with child-rearing behaviors than mother-related health behaviors," Journal of Public Health Dentistry, vol. 69, no. 2, pp. 104-110, 2009.

[44] D. W. Baker, M. V. Williams, R. M. Parker, J. A. Gazmararian, and J. Nurss, "Development of a brief test to measure functional health literacy," Patient Education and Counseling, vol. 38, no. 1, pp. 33-42, 1999.

[45] B. A. Dye, S. Tan, V. Smith et al., "Trends in oral health status: United States, 1988-1994 and 1999-2004," National Center for Health Statistics. Vital Health Statistics, vol. 11, no. 248, pp. 192, 2007.

[46] American Academy of Pediatric Dentistry, "Policy on use of a caries-risk assessment tool (CAT) for infants, children, and adolescents," Pediatric Dental Journal, vol. 29, no. 7, supplement, pp. 29-33, 2007.

[47] American Dental Association, "Caries Form (Patients 0-6)," 2008, http://www.ada.org/prof/resources/topics/topics_caries_ under6.doc.

[48] F. J. Ramos-Gomez, J. Crall, S. A. Gansky, R. L. Slayton, and J. D. Featherstone, "Caries risk assessment appropriate for the age 1 visit (infants and toddlers)," Journal of the California Dental Association, vol. 35, no. 10, pp. 687-702, 2007.

[49] D. Young, J. Featherstone, Roth Jr., et al., "Consensus statement caries management by risk assessment: implementation guidelines to support oral health," Journal of the California Dental Association, vol. 35, no. 11, pp. 799-805, 2007.

[50] J. J. Warren, K. Weber-Gasparoni, T. A. Marshall et al., "A longitudinal study of dental caries risk among very young low SES children," Community Dentistry and Oral Epidemiology, vol. 37, no. 2, pp. 116-122, 2009.

[51] P. A. Weiss, C. S. Czerepak, K. J. Hale et al., "Oral health risk assessment timing and establishment of the dental home," Pediatrics, vol. 111, no. 5, pp. 1113-1116, 2003.
[52] American Academy of Pediatrics' (AAP) Section of Pediatric Dentistry and Oral Health, "Policy statement: preventive oral health intervention for pediatricians," Pediatrics, vol. 122, no. 6, pp. 1387-1394, 2008.

[53] American Academy of Pediatric Dentistry, "Policy on early childhood caries: classifications, consequences, and preventive strategies," Pediatric Dentistry, vol. 30, no. 7, supplement, pp. 40-43, 2008.

[54] R. G. Rozier, C. Stearns, BT Pahel, and R. B. Quiñonez, Research Brief: Evaluation of into the Mouth of Babes Program, The University of North Carolina, Chapel Hill, NC, USA, 2007.

[55] B. L. Edelstein, R. J. Manski, and J. F. Moeller, "Pediatric dental visits during 1996: an analysis of the federal Medical Expenditure Panel Survey," Pediatric Dentistry, vol. 22, no. 1, pp. 17-20, 2000. 


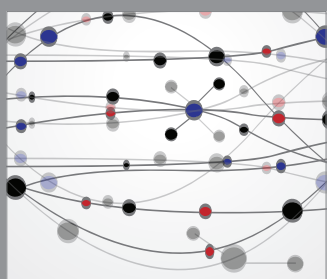

The Scientific World Journal
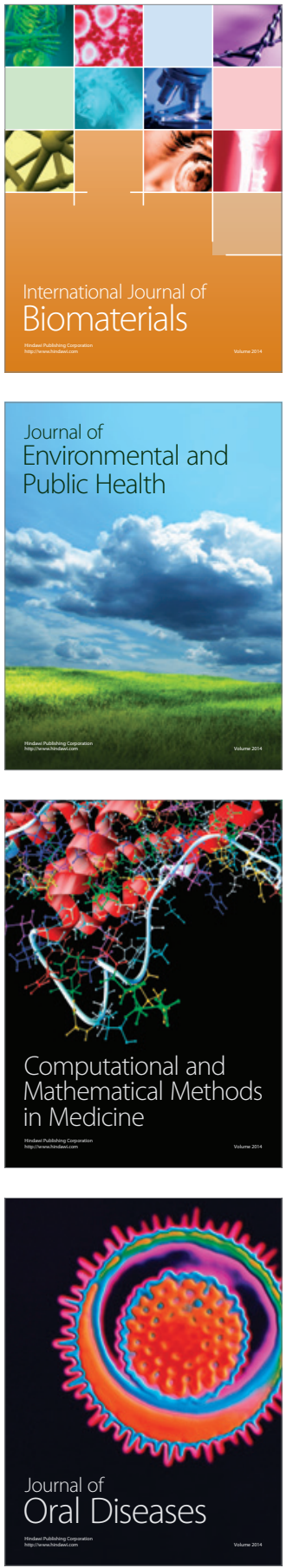
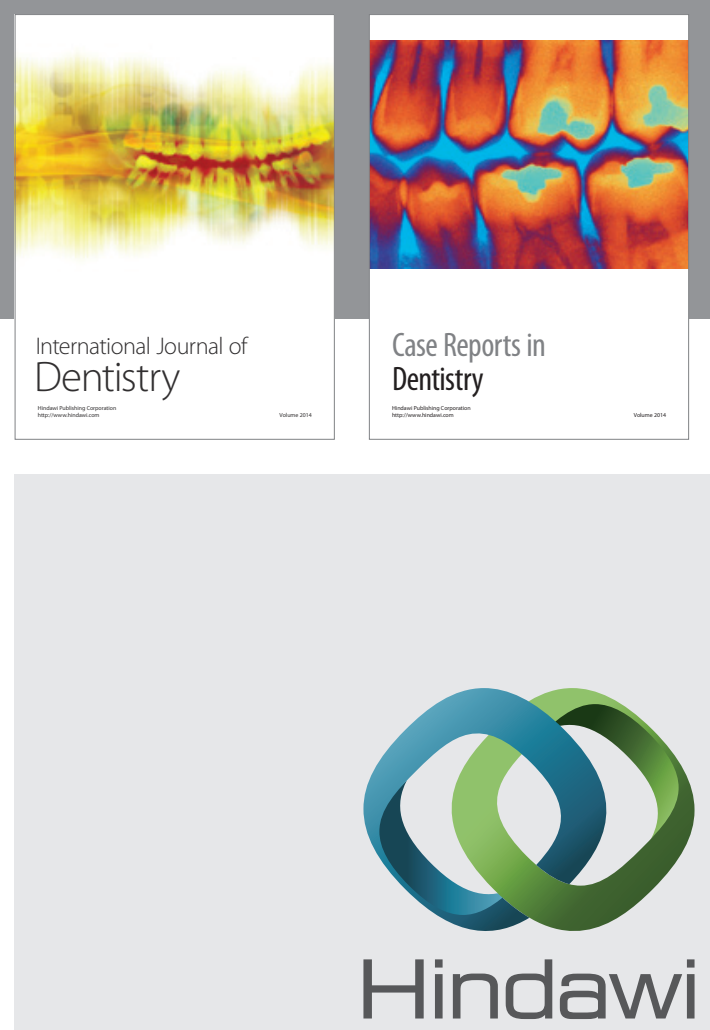

Submit your manuscripts at

http://www.hindawi.com
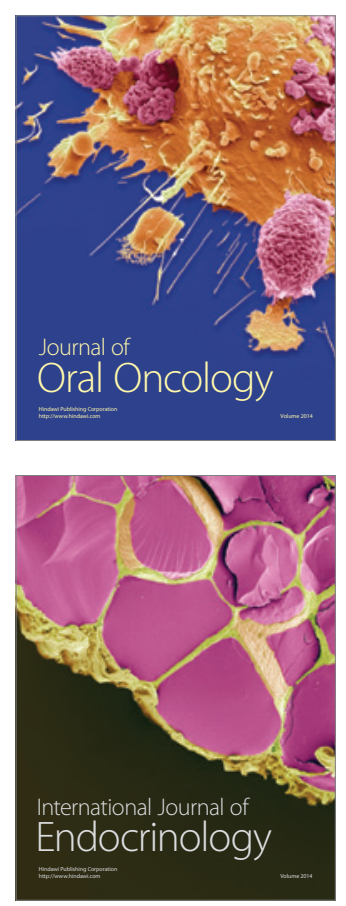
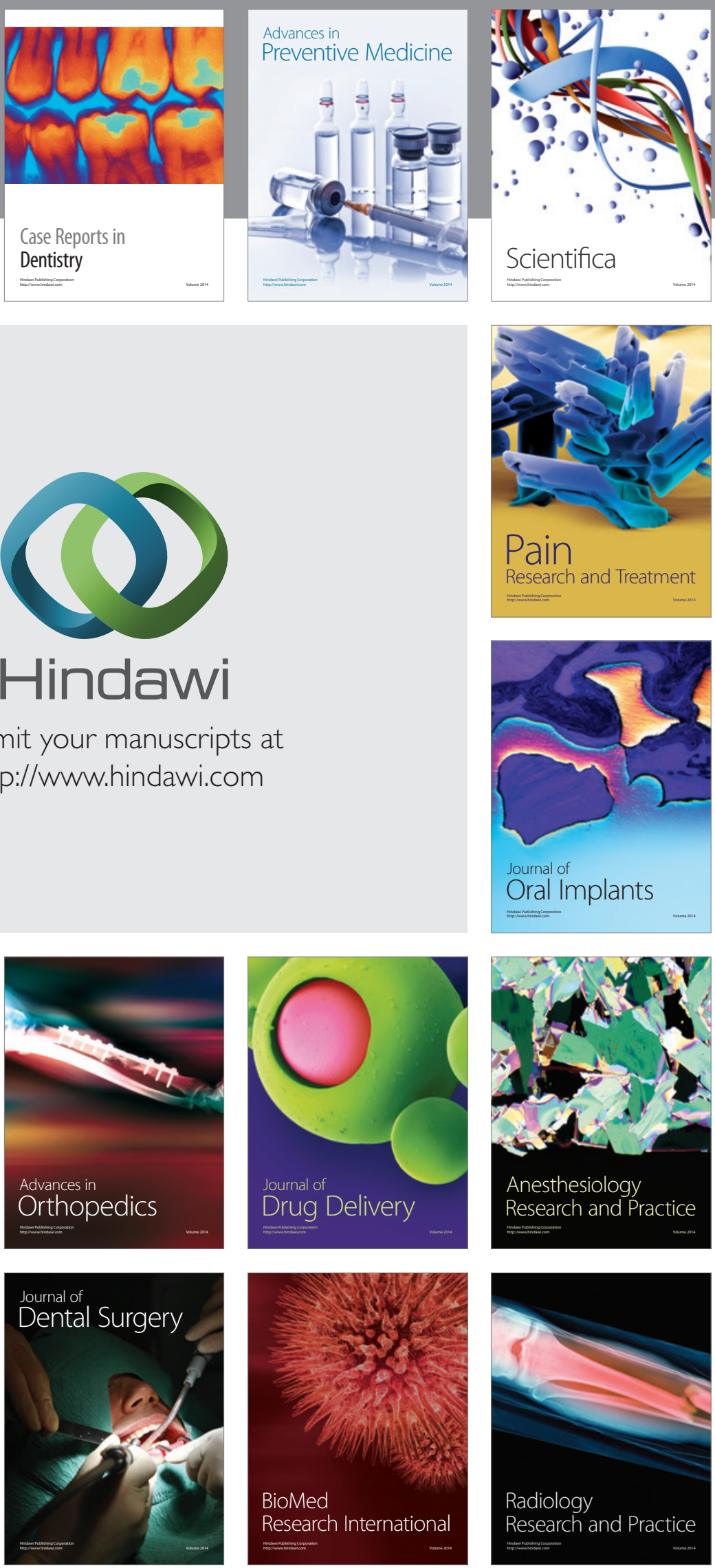